\title{
The New Smart-Meds: Redesign of a Gamified App to Improve Medication Adherence Using a Mixed Methods Design
}

\author{
Arnaud RICCI ${ }^{\mathrm{a}, 1}$, Laetitia GOSETTO ${ }^{\mathrm{b}}$, \\ Katherine BLONDON ${ }^{\mathrm{a}, \mathrm{b}}$ and Frédéric EHRLER ${ }^{\mathrm{a}}$ \\ ${ }^{\text {a } U n i v e r s i t y ~ H o s p i t a l s ~ o f ~ G e n e v a, ~ S w i t z e r l a n d ~}$ \\ ${ }^{\mathrm{b}}$ University of Geneva, Switzerland
}

\begin{abstract}
SMART-MEDS is a gamification-based mobile application to improve medication adherence. In its first version, it relied on storytelling to bolster user engagement. The feedback collected from users after one month testing revealed that although they appreciated the proposed story, they did not find it compelling enough. On the positive side they really appreciated to learn about their medications and disease through a dedicated quiz. In this paper, we present a new version of the app redesigned based on the collected feedback. We have based ourselves on the theories of gamification and self-efficiency to propose new mechanics such as minigames, and interactive dialogues with a chatbot. Everything is wrapped up inside a new story that takes us on a journey through Switzerland. We also tried to reinforce the app educational aspects by integrating documentation directly inside the new mechanics. This new app seems to address all the issues raised during the first user tests, and will be tested in the near future.
\end{abstract}

Keywords. Mobile, application, gamification, health, medication adherence, coronary artery disease, game, elderly people, treatment

\section{Introduction}

SMART-MEDS is a gamified application aimed at improving medication adherence. According to a 2003 WHO report, 50\% of people taking medication adhere poorly or not at all [1]. Our target population are individuals with coronary heart disease who require daily medication. This disease mainly affects people over 60 years old [2].

The literature highlights several factors that reduce adherence. These are: lack of confidence in the ability to take treatment over the long term (self-efficacy); lack of knowledge and understanding of the risks of the disease, and the patient's inadequate expectations about the treatment. The mismatch between the expected and the perceived benefits of treatment may also play an important role in medication adherence [1].

As an attempt to act on these factors we developed a first application in 2018 with an editable medication plan, in which medication reporting was encouraged through gamification strategies (Figure 1). Indeed, gamification makes it possible to increase intrinsic motivation and encourage the practice of good behaviors [4]. In the original

1 Arnaud Ricci, University Hospitals of Geneva, Rue Gabrielle-Perret-Gentil 4, 1205 Geneva, Switzerland; E-mail: Arnaud.ricci@hcuge.ch. 
concept the mobile application that included a quiz as well as the use of storytelling and the visualization of progression [3].
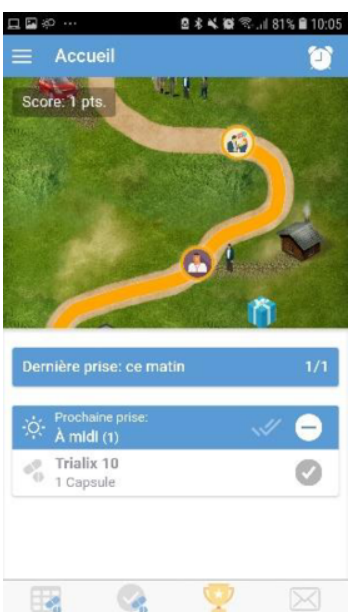
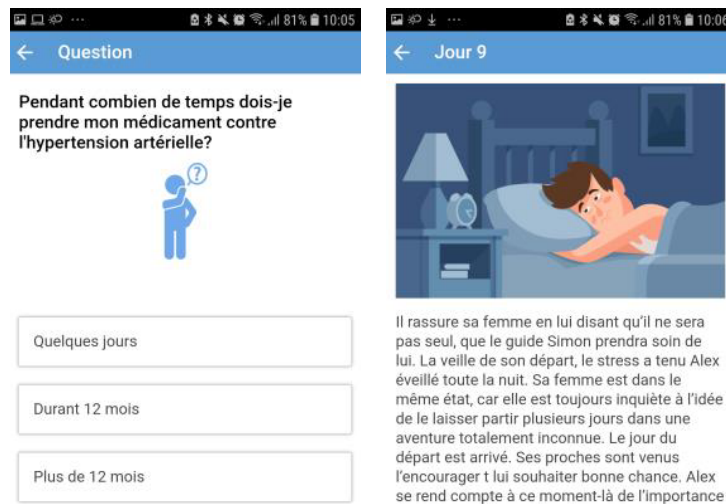

II rassure sa femme en lui disant quiil ne sera pas seul, que le guide Simon prendra soin de lui. La veille de son départ, le stress a tenu Alex éveillé toute la nuit. Sa femme est dans le même état, car elle est toujours inquiète à lídée de le laisser partir plusieurs jours dans une aventure totalement inconnue. Le jour du départ est arrivé. Ses proches sont venus lencourager $t$ lui souhaiter bonne chance. Alex de cette aventure qui va changer sa vie à jamais.

Fermer

Figure 1. Home screen, quiz and storytelling of the first smart-meds application

In the original concept, a story was the central pillar to engage users. A realistic narrative was created to incite the user to adopt the goals and plans of the story's character, projecting themselves through the various stages of the change process. A new part of story is revealed daily when the patient records her medication intake [3].

In this article, we present the revised design of this gamified app, after taking into account the feedback received about the first version: the new concept integrates new features based on the theories of gamification [4] [5] and self-efficacy [6].

\section{Methodology}

We combined several inputs form users as well as from the literature in order to guide our design process. We collected the feedback from a group of 18 individuals with coronary heart disease that have tested the original app during a period of 30 days. The participants provided their feedback regarding the main functionalities and its gamification strategies (reported elsewhere, manuscript submitted).

Since the objective of the new concept was to increase engagement, we browsed the literature to propose new gamification mechanisms than can support this goal. We also reflected on how to reinforce educational aspects of the app by integrating information directly in the new mechanics.

\section{Results}

We learned from participants' feedback that they appreciated learning about their disease and medication. They also like the quizzes, and found the story interesting but not compelling enough to drive app use or better medication adherence. 
Based on this first input we defined our new gaming application concept around a trip in Switzerland. The user embodies a person who wants to learn more about our country and to adopt a healthier behavior in relation to her disease.

During her journey, she will discover several Swiss cities. In these cities, the app offers the possibility of playing mini-games. Our first concept highlighted the attractiveness of the quiz for our target audience. This interest was confirmed by studies showing that older people prefer puzzle-type casual games [7, 8]. Therefore, we complemented the quiz with additional mini-games such as crosswords and word searches. In order to integrate an educational aspect, we designed the mini-games so that their answers were linked to a health thematic.

During her journey, she will also meet different people such as a nutritionist or a sports coach who will teach him about her health, her disease, and the treatments. All the new features are identified from theoretical models of behavioral change and gamification theories [4] [5] [7] such as Tondello's Hexad Scale player profile [8], flow theory [9] and Bandura's self-efficacy theory [6] to increase adherence and knowledge about the disease (Figure 2). These features are presented below.

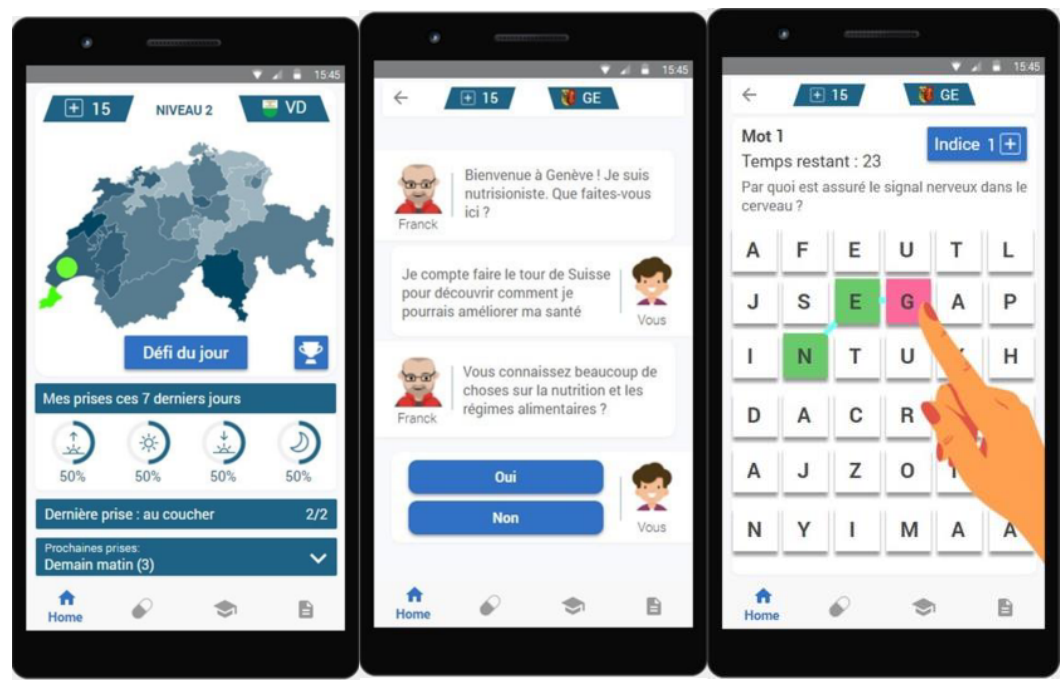

Figure 2. Home screen, dialog screen and mini-game screen

\subsection{Putting the user at the center of the story}

The impact of the story on the reader's attitude depends on her involvement within the story [10]. It's why it seemed essential to change the user's perspective, not only suggesting that she identifies with the main character, but involving him as the main character of the story. The aim is to increase her involvement with the story.

In the new concept, the user creates their own avatar, which appears throughout the levels. For example, during the dialogues with the chatbot (see below), the face of the avatar is displayed next to our dialogues. This helps the user to be more involved in the virtual environment [11] and helps increase user identification [6]. 


\subsection{Adapting to the user's "player profile"}

Several scales have been developed to identify the profile of players, to know what their preferences are in terms of games and mechanics. One of these scales is the Hexad Scale developed by Tondello. Hexad Scale developed by Tondello. On this scale which defines 6 user profiles (Disruptor, Philanthropist, Socializer, Player, Free spirit, and Achiever) we kept three of these profiles to build our concept because it is difficult to integrate all the profils [8].

Among the profile defined in the Hexad framework, Achievers want to be competent in whatever they do. They like to complete all the tasks and levels and to take on the difficult challenges [8]. The visualization of progress through levels provides feedback about what she has already achieved [6]. In our new design, the progress is represented through a path in the map of Switzerland that shows the cities as levels.

Other Hexad profile such as "Player" concerns users who are highly motivated by extrinsic rewards. They will strive to earn a reward, such as badges or points, regardless of the type of activity. [8] For these users, we devised a badge system, which is rewarded after playing 5 mini-games of a given theme. According to Bandura's theory of selfefficacy [6], in order to encourage the user, we included smaller sub-goals to help achieve the final goal. The badges therefore represent the sub-goals to be achieved. Additionally, these badges provide clear objectives and immediate feedback, which is one of the dimensions for achieving the state of flow [9]. This state of flow is a driver for intrinsic motivation. According to the flow theory, the player's skill must equal the difficulty of the game for the player to be in a state of flow (in a state of concentration that is entirely dedicated to the game). If the game is too simple, the player will see no interest in it, but if the game is too difficult, she will exceed her abilities and will discourage him from continuing to play it. Thus, the difficulty of the games increases every 5 games to adapt to the skills that the player has acquired while playing.

\subsection{Improving interactions}

Chatbots have already proven their effectiveness in several medical fields such as neurological disorders or addictions [12]. In particular, they allow the collection of data on the patient's condition, facilitate the transmission of information, and can coach the patient to change their behaviors by motivating and counselling them [12].

In our concept, the user interacts with a chatbot in several contexts during the tour of Switzerland. The user participates in interactive dialogues with different characters that are used to construct the story during the tour. This is an important element for the screenplay, and allows more scripted transitions between the different stages of the story.

Introducing several characters with the chatbot systems also allows the user to learn about their health, their treatments, or their disease. Through these different characters, the chatbot can also motivate the user in response to the answers she provides. The use of various characters also allows us to address some of the Hexad profiles such as the Socializer and Philanthropist profiles, who are driven by interactions and well-intended actions.

\subsection{Reward system}

Rewards are important to motivate users to get involved in a real setting [4]. To encourage users to take their medication, we have devised a reward system where users 
receive health points when they document their intake of medication. These health points can be spent in several ways: they can help the user to complete the mini-games by providing clues. The user can only play 2 mini-games per day. Once the 2 daily minigames are finished, she will have to spend 1 health point to start a new mini-game. If the user fails at a mini-game, a health point can allow him to restart the mini-game, otherwise she will have to wait until the next day. Health points can also help the user advance faster in the story. Moreover, this health point reward system can help motivate those who appreciate to get rewards and collect points (i.e., Hexad Players and Achievers). [8]

\section{Conclusion}

As demonstrated in numerous studies, gamification has a real potential to drive behavioural changes. However, defining a suitable concept is not simple. It is necessary to design solutions adapted to the preferences of users, which are heterogeneous. In this article, we propose a new concept supported by the main theories of gamification and behavioural change. The gamified concept we propose needs to be evaluated with the target audience, in terms of engagement and in improving medication adherence. Therefore, the next step will be to test this new design on the target users to see if it meets their needs.

In the future we would like to generalize this gamified concept to users with other diseases; we also aim to target other age groups. Once again, further adaptations and user tests will be needed.

\section{References}

[1] Schneider MP, Herzig L, Hugentobler and others. Adhésion thérapeutique du patient chronique : des concepts à la prise en charge ambulatoire. Rev Med Suisse. 2013; 9: 1032-1036.

[2] Mozaffarian D, Benjamin EJ, Go AS, and others. Executive summary: heart disease and stroke statistics - 2015 update: a report from the American Heart Association. Circulation. 2015; 131(4): 434-441.

[3] Ehrler F, Gschwind L, Meyer P, and others. SMART-MEDS: Development of a Medication Adherence App for Acute Coronary Syndrome Patients based on a Gamified Behaviour Change Model.Proceedings of the AMIA Annual Symposium; San Francisco; 2018. 413 p.

[4] Nicholson S. A recipe for meaningful gamification. In Gamification in education and business. Springer, Cham, 2015. Chapter 1; p. 1-20.

[5] Johnson D, Deterding S, Kuhn K. A and others. Gamification for health and wellbeing: A systematic review of the literature. Internet interventions. 2016; 6: 89-106.

[6] Bandura A. Self-Efficacy The Exercise of Control. New York: W. H. Freeman; 1997.

[7] Abraham, O., Thakur, T., \& Brown, R. Developing a Theory-Driven Serious Game to Promote Prescription Opioid Safety Among Adolescents: Mixed Methods Study. JMIR Serious Games. 2020; 8(3), $1-13$.

[8] Tondello GF, Wehbe RR, Diamond L, and others. The gamification user types hexad scale. Proceedings of the 2016 annual symposium on computer-human interaction in play. 2016 Oct; Austin, TX. 229-243 p.

[9] Csikszentmihalyi M. The Evolving Self: A Psychology for the Third Millennium. New York: HarperCollins; 1993.

[10] Dal Cin S, Zanna MP, Fong GT. Narrative persuasion and overcoming resistance. Resistance and persuasion. 2004; 2, 175-191.

[11] Lim S, Reeves B. Computer agents versus avatars: Responses to interactive game characters controlled by a computer or other player. International Journal of Human-Computer Studies. 2010; 68(1-2): 57-68.

[12] Pereira J, Díaz Ó. Using health chatbots for behavior change: a mapping study. Journal of medical systems. 2019; 43(135), 1-13. 